\title{
Development of SI Traceable Standards for Element Determination
}

\author{
Heinrich Kipphardt*a, Ralf Matschat ${ }^{a}$, and Ulrich Panne ${ }^{\mathrm{ab}}$
}

\begin{abstract}
In Germany a system of primary amount of substance standards for elemental analysis is being developed, which forms the material's basis for the National Standards for element determination. The metrological concept and technical approach is briefly described. The objective of traceability in chemistry, in this case for elemental determination, is illustrated on the example of copper.
\end{abstract}

Keywords: Copper $\cdot$ Element determination $\cdot$ Metrology $\cdot$ Primary standards $\cdot$ Traceability

\section{Introduction}

Comparability of measurement results in time and space is an important prerequisite for scientific and economic progress. A tool to achieve this comparability is to establish metrological traceability of the measurement results to the values defined by the International System of Units (SI). Since a measurement involves an experimental comparison, the values defined in the abstract definition of the SI need to be physically embodied in so called primary measurement standards. This holds also for chemical measurements where especially the identity of a substance matters. ${ }^{[1]}$ For chemical measurements, standards are materials that carry abstract values for defined characteristics. Since in chemical analy-

${ }^{*}$ Correspondence: Dr. H. Kipphardta

Tel.: +49 3081041116

Fax: +493081041117

E-Mail: heinrich.kipphardt@bam.de

aAM Bundesanstalt für Materialforschung

und -prüfung

Richard-Willstätter-Str. 11

12489 Berlin, Germany

bDepartment of Chemistry

Humboldt Universität zu Berlin

Brook-Taylor-Strasse 2

12489 Berlin, Germany sis the measurement procedure depends strongly on the analyte and the matrix, it is very convenient to have a standard of the specific substance, whose amount or other property is being measured. For the field of element determination a standard for each element of the periodic table would be very convenient. High purity materials can be useful primary standards, however, only if the purity is actually known. Since there is no method of measurement to measure the purity of a matrix element in a pure substance with sufficiently small uncertainty, the purity needs to be measured by the indirect approach. This approach encompasses the measurement of the mass fractions of all relevant impurities and the value for purity is estimated by subtracting the sum of the impurities from the ideal purity of $100 \%$. It is observed, that in chemical analysis it is state-of-the-practice to use high purity materials supplied with a 'certificate' from the manufacturer as primary standards. These certificates or information are usually based on measurement results for a few metallic impurities that have been measured by the manufacturer often by semi-quantitative methods, and do not include an uncertainty statement. Values for the content of non-metals in such high purity metals are usually not taken into account. The term used in the purity statement is 'metals basis'. While for many applications these certificates are fit for the intended use, the values provided on these certificates for this 'partial' purity are taken by the analyst synonymously for the total impurity of the material. This is wrong of course. However, most often no comprehensive information is available for the material. A tutorial example on how this approach can fail is illustrated in Table 1 for analysis of 'pure' copper. When aiming at amount of substance standards, values for all impurities must be considered and these values must be accompanied by an uncertainty statement according to GUM. [2]

At BAM a system of primary standards for element analysis with high metrological quality is being developed. ${ }^{[3,4]}$ In close collaboration with the German National Metrology Institute - Physikalisch-Technische Bundesanstalt (PTB in Braunschweig), this system forms the material's basis for the National Standards for element determination in Germany. The aim of these activities is to certify the mass fraction of the matrix element in a high purity metal with a target uncertainty of $10^{-4}$ relative according to GUM. This uncertainty is about one order of magnitude lower than what is required even for most metrological and other applications. The indirect approach is followed for certification, however, all elements of the periodic table not being the matrix element are considered. This does not only include other metallic impurities but also includes the non-metals. Especially oxygen, but also hydrogen and the halogens, can be the main impurity in a high purity metal. Some of the impuri-

Table 1. Comparison of the mass fractions of copper in two different materials based on the metallic impurities (as given by the supplier 'metals basis') and on the total impurities as measured.

\begin{tabular}{|c|c|c|c|c|}
\hline \multirow[b]{2}{*}{$\begin{array}{l}\text { metals basis - as given by } \\
\text { the supplier }\end{array}$} & \multicolumn{2}{|c|}{ BAM-Y001 } & \multicolumn{2}{|c|}{ BAM-B-primary-Cu-1 } \\
\hline & $\mathrm{m} 4 \mathrm{~N}$ & 0.9999 & $\mathrm{~m} 6 \mathrm{~N}$ & 0.999999 \\
\hline total - as measured at BAM & $\mathrm{t}_{4} \mathrm{~N}_{69}$ & $0.999969 \pm 0.000010$ & $\mathrm{t}^{3} \mathrm{~N}_{44}$ & $0.99944 \pm 0.017$ \\
\hline
\end{tabular}


ties, especially oxygen, contribute with a fraction from bulk and surface of the metal lumps. Therefore, the value certified applies only to the material being in a welldefined state. This involves a prescribed surface treatment of the metal pieces, a limit for the surface to volume ratio and a time table for processing.

The impurities are measured using a variety of measurement methods and techniques. For impurity elements found above the limit of quantification (LOQ; $9 \cdot s$ criterion), the value measured is used in the calculation, and an uncertainty of at least $30 \%$ relative is conservatively applied, even if the uncertainty statement from the measurement is much smaller. For values below the LOQ, a value of half of the LOQ is used in the calculation, and an uncertainty of $100 \%$ relative is applied. As long as the material is of high purity, rather large relative uncertainties can be tolerated. Usually few elements dominate the impurity statement. For each of these elements, independent methods of measurement are applied where possible. Other certified matrix reference materials are measured in the same series to check for the consistency of the measurement results (see ref. [5] for the example of copper). Due to the limited amount of material available, the materials certified are only available to other National Metrology Institutes (NMIs). The distribution of the calibration capability to the field laboratories is performed by the NMIs via co-operation with producers of commercial calibration solutions as exemplified by Kipphardt et al. ${ }^{[6]}$

\section{Material and Methods}

A copper material (indicated purity 99.99\%) from Alfa JM in the form of spherical objects with a diameter of about $12 \mathrm{~mm}$ was used. It was chemically treated before analysis according to a procedure developed at the Bureau Commission of Reference (BCR) that is today IRMM in Geel, Belgium. ${ }^{[7]}$ Electrogravimetry was used for the direct measurement of the copper mass fraction. A correction for the trace content of silver was applied. Atomic spectrometry (High Resolution Inductively Coupled Plasma with Mass Spectrometry (HR-ICP-MS), Inductively Coupled Plasma with Optical Emission Spectrometry (ICP OES), Electro Thermal Atomic Absorption Spectrometry (ET AAS) and Cold Vapour Atomic Absorption Spectrometry (CV AAS)), spectrophotometric methods for $\mathrm{S}$ and $\mathrm{P}$, photon activation analysis (PAA) and carrier gas hot extraction (CGHE) for $\mathrm{O}, \mathrm{N}$, and $\mathrm{C}$, nuclear reaction analysis (NRA) for $\mathrm{H}$ and instrumental neutron activation analysis (INAA) were applied. Noble gases were measured at Max-Planck-Institute for Chemistry, Mainz using the procedure described by Schelhaas and therein cited references. ${ }^{[8]}$ For the radioactive elements (Tc, Pm, Po, At, Rn, Fr, Ra, $\mathrm{Ac}, \mathrm{Pa}$ ), reasonable upper limit estimates have been made.

\section{Results and Discussion}

In the Fig. the results obtained for the impurity measurement on the primary standard BAM-Y001 are summarised with all relevant elements of the periodic table being determined. Elements found above the limit of quantification are marked with darker grey background. For these elements, especially for the main impurity silver, independent methods of measurement have been used where possible. The results are summarised in Table 2. They show good consistency, especially when keeping the uncertainty statement of $30 \%$ relative in mind. For iron, there seems to be a contamination of individual copper spheres, which required an estimation of a conservative upper limit. The result for the mass fraction of copper using the indirect approach is $w(\mathrm{Cu}, \mathrm{BAM}-\mathrm{Y} 001)$ $=0.999969 \pm 0.000010$ (where the expanded uncertainty $U=u_{\mathrm{c}} \cdot k$ with $k=2$ is given). ${ }^{[9,10]}$ This value is consistent with the value of $w(\mathrm{Cu}, \mathrm{BAM}-\mathrm{Y} 001)=0.999$ $9 \pm 0.0002(k=2)$ obtained by electrogravimetry.

\section{Conclusions}

Primary standards with demonstrated SI traceable values are indispensable for an effective measurement system. This holds also for element determination, where there is still a lack of such standards. The certification of such materials was demonstrated to be feasible but technically challenging due to the comprehensive nature of the characterisation. Up to now ten elements have been certified as primary standards, others are in progress. ${ }^{[11]}$

BAM-Y001

\begin{tabular}{lrrrr} 
& $\begin{array}{l}\text { matrix } \\
\text { in \% }\end{array}$ & $\begin{array}{r}\text { impurity } \\
\text { in } \\
\mathrm{mg} \cdot \mathrm{kg}^{-1}\end{array}$ & $\begin{array}{c}\text { sum } \\
\text { 'above' } \\
\text { in } \\
\mathrm{mg} \cdot \mathrm{kg}^{-1}\end{array}$ & $\begin{array}{c}\text { sum/2 } \\
\text { 'below' } \\
\text { in }\end{array}$ \\
\hline mass fraction & 99.9970 & 30 & 22 & 8 \\
abs. uncertainty & 0.0005 & 5 & 4 & 3 \\
\hline
\end{tabular}

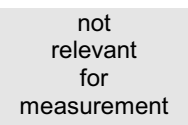

\begin{tabular}{|c|c|c|c|c|c|c|c|c|c|c|c|c|c|c|c|c|c|}
\hline $\begin{array}{c}\mathrm{H} \\
<2.1\end{array}$ & & & & & & & & & & & & & & & & & $\begin{array}{c}\mathrm{He} \\
<0.001\end{array}$ \\
\hline $\begin{aligned} & \mathrm{Li} \\
< & 0.31\end{aligned}$ & $\begin{array}{c}\mathrm{Be} \\
<0.2\end{array}$ & & & & & & & & & & & $\begin{array}{c}\mathrm{B} \\
<3.2\end{array}$ & $\begin{array}{c}C \\
0.04\end{array}$ & $\begin{array}{l}\mathrm{N} \\
0.2\end{array}$ & $\begin{array}{l}0 \\
1\end{array}$ & $\begin{array}{c}F \\
<3\end{array}$ & $\begin{array}{c}\mathrm{Ne} \\
<0.001\end{array}$ \\
\hline $\begin{array}{c}\mathrm{Na} \\
0.002\end{array}$ & $\begin{array}{c}\mathrm{Mg} \\
0.004\end{array}$ & & & & & & & & & & & $\begin{array}{c}\mathrm{Al} \\
<0.07\end{array}$ & $\begin{array}{c}\mathrm{Si} \\
<0.2\end{array}$ & $\begin{array}{l}\mathrm{P} \\
<2\end{array}$ & $\begin{array}{c}S \\
5.4\end{array}$ & $\begin{array}{c}\mathrm{Cl} \\
<0.6\end{array}$ & $\begin{array}{c}\mathrm{Ar} \\
<0.001\end{array}$ \\
\hline $\begin{array}{c}\mathrm{K} \\
<0.002\end{array}$ & $\begin{array}{l}\mathrm{Ca} \\
0.06\end{array}$ & $\begin{aligned} & S c \\
< & 0.06\end{aligned}$ & $\begin{aligned} & \mathrm{Ti} \\
< & 0.32\end{aligned}$ & $\begin{array}{c}V \\
<0.04\end{array}$ & $\begin{array}{c}\mathrm{Cr} \\
0.05\end{array}$ & $\begin{array}{l}\mathrm{Mn} \\
0.01\end{array}$ & $\begin{array}{c}\mathrm{Fe} \\
<0.8\end{array}$ & $\begin{array}{c}\text { Co } \\
<0.11\end{array}$ & $\begin{array}{l}\mathrm{Ni} \\
1.64\end{array}$ & $\begin{array}{c}\mathrm{Cu} \\
\text { matrix }\end{array}$ & $\begin{array}{c}\mathrm{Zn} \\
0.057\end{array}$ & $\begin{aligned} & \mathrm{Ga} \\
< & 0.11\end{aligned}$ & $\begin{aligned} & \mathrm{Ge} \\
< & 0.12\end{aligned}$ & $\begin{array}{l}\text { As } \\
0.5\end{array}$ & $\begin{array}{l}\mathrm{Se} \\
0.22\end{array}$ & $\begin{aligned} & \mathrm{Br} \\
< & 0.014\end{aligned}$ & $\begin{array}{c}\mathrm{Kr} \\
<0.001\end{array}$ \\
\hline $\begin{array}{c}\mathrm{Rb} \\
<0.05 \\
\end{array}$ & $\begin{array}{c}\mathrm{Sr} \\
<0.014 \\
\end{array}$ & $\begin{array}{c}\mathrm{Y} \\
<0.03 \\
\end{array}$ & $\begin{array}{c}\mathrm{Zr} \\
<0.015 \\
\end{array}$ & $\begin{array}{c}\mathrm{Nb} \\
<0.02 \\
\end{array}$ & $\begin{array}{c}\text { Mo } \\
<0.06 \\
\end{array}$ & \begin{tabular}{|c|} 
Tc \\
$<0.001$ \\
\end{tabular} & \begin{tabular}{|c|}
$\mathrm{Ru}$ \\
$<0.03$ \\
\end{tabular} & \begin{tabular}{|c|}
$\mathrm{Rh}$ \\
$<1.6$ \\
\end{tabular} & \begin{tabular}{|c|}
$\mathrm{Pd}$ \\
$<0.014$ \\
\end{tabular} & \begin{tabular}{|l|}
$\mathrm{Ag}$ \\
11.3 \\
\end{tabular} & $\begin{array}{c}\mathrm{Cd} \\
<0.015 \\
\end{array}$ & $\begin{array}{l}\ln \\
<0.05 \\
\end{array}$ & $\begin{array}{l}\mathrm{Sn} \\
0.14 \\
\end{array}$ & $\begin{array}{c}\mathrm{Sb} \\
1 \\
\end{array}$ & \begin{tabular}{|c|}
$\mathrm{Te}$ \\
$<0.22$ \\
\end{tabular} & $\begin{array}{c}1 \\
<0.09 \\
\end{array}$ & $\begin{array}{c}\mathrm{Xe} \\
<0.001 \\
\end{array}$ \\
\hline $\begin{array}{c}\mathrm{Fr} \\
<0.001 \\
\end{array}$ & $\begin{array}{c}\mathrm{Ra} \\
<0.001 \\
\end{array}$ & $\begin{array}{c}\mathrm{Ac} \\
<0.001\end{array}$ & & & & & & & & & & & & & & & \\
\hline & & & $\begin{array}{c}\mathrm{Ce} \\
<0.006\end{array}$ & $\begin{array}{c}\mathrm{Pr} \\
<0.002\end{array}$ & $\begin{array}{c}\mathrm{Nd} \\
<0.21\end{array}$ & $\begin{array}{c}\mathrm{Pm} \\
<0.001\end{array}$ & $\begin{array}{c}\mathrm{Sm} \\
<0.007\end{array}$ & $\begin{array}{c}\mathrm{Eu} \\
<0.003\end{array}$ & $\begin{array}{c}\mathrm{Gd} \\
<0.001\end{array}$ & $\begin{array}{c}\mathrm{Tb} \\
<0.001\end{array}$ & $\begin{array}{c}\text { Dy } \\
<0.001\end{array}$ & $\begin{array}{c}\mathrm{Ho} \\
<0.001\end{array}$ & $\begin{array}{c}\mathrm{Er} \\
<0.001\end{array}$ & $\begin{array}{c}\mathrm{Tm} \\
<0.001\end{array}$ & $\begin{array}{c}\mathrm{Yb} \\
<0.001\end{array}$ & $\begin{array}{c}\mathrm{Lu} \\
<0.002\end{array}$ & \\
\hline & & & $\begin{array}{c}\text { Th } \\
<0.02\end{array}$ & $\begin{array}{c}\mathrm{Pa} \\
<0.001\end{array}$ & $\begin{array}{c}U \\
<0.001\end{array}$ & & & & & & & & & & & & \\
\hline
\end{tabular}

Fig. Measurement results for the purity assessment of copper material BAM-Y001 (< means limit of determination, values in mg $\mathrm{kg}^{-1}$ ). 
Table 2. Comparison of results for the mass fractions $w$ obtained with different measurement techniques for impurities found above the limit of determination in BAM-Y001 metallic high purity copper.

\begin{tabular}{|c|c|c|}
\hline & $w /\left(\mathrm{mg} \cdot \mathrm{kg}^{-1}\right)$ & method \\
\hline \multirow[t]{4}{*}{$\mathrm{Ag}$} & 11.3 & ET AAS \\
\hline & 10.6 & INAA \\
\hline & 11.3 & ICP OES \\
\hline & 11.3 & HR-ICP-MS \\
\hline \multirow[t]{2}{*}{$\mathrm{Ni}$} & 1.7 & ET AAS \\
\hline & 1.6 & HR-ICP-MS \\
\hline \multirow[t]{2}{*}{$\mathrm{O}$} & 1 & PAA \\
\hline & 1 & CGHE \\
\hline \multirow[t]{3}{*}{$\mathrm{Sb}$} & 0.99 & ET AAS \\
\hline & 0.83 & INAA \\
\hline & 1.02 & HR-ICP-MS \\
\hline \multirow[t]{2}{*}{$\mathrm{N}$} & 0.6 & PAA \\
\hline & 0.2 & CGHE \\
\hline \multirow[t]{2}{*}{ As } & 0.5 & ET AAS \\
\hline & 0.5 & HR-ICP-MS \\
\hline \multirow[t]{2}{*}{$\mathrm{Pb}$} & 0.46 & ET AAS \\
\hline & 0.49 & HR-ICP-MS \\
\hline \multirow[t]{2}{*}{$\mathrm{Bi}$} & 0.28 & ET AAS \\
\hline & 0.17 & HR-ICP-MS \\
\hline \multirow[t]{2}{*}{ Sn } & 0.14 & ET AAS \\
\hline & 0.15 & HR-ICP-MS \\
\hline \multirow[t]{2}{*}{$\mathrm{Ca}$} & 0.1 & ET AAS \\
\hline & 0.1 & ICP OES \\
\hline \multirow[t]{2}{*}{$\mathrm{Cr}$} & 0.08 & ET AAS \\
\hline & 0.06 & HR-ICP-MS \\
\hline
\end{tabular}

\section{Acknowledgements}

The authors would like to thank the laboratory of Dr. U. Ott, Max-Planck-Institut für Chemie, Mainz for the measurement of the noble gases, and all colleagues of BAM for their experimental contribution.

Received: June 25, 2009

[1] H. Kipphardt, R. Matschat, U. Panne, Mikrochim. Acta 2008, 162, 35.

[2] 'Guide to the expression of uncertainty in measurement', ISO, Geneva, 1993.

[3] R. Matschat, H. Kipphardt, ERZMETALL 2003, 56, 179.

[4] R. Matschat, M. Czerwensky, S. Pattberg, H.-J. Heinrich, S. Tutschku, Mat. Trans. (JIM) 2002, 43, 90.

[5] B. Lange, S. Recknagel, M. Czerwensky, R. Matschat, M. Michaelis, B. Peplinski, U. Panne, Mikrochim. Acta 2008, 160, 97.

[6] H. Kipphardt, R. Matschat, O. Rienitz, D. Schiel, W. Gernand, D. Oeter, Accred. Qual. Assur. 2006, 10, 633.

[7] G. Weber, D. David, L. Quaglia, J. Pauwels, J. Van Audenhove, J. Radioanal. Chem. 1977, 39, 343.

[8] N. Schelhaas, U. Ott, F. Begemann, Geo. Cosmochim. Acta 1990, 54, 2869.

[9] 'Certification of the mass fraction of copper in primary reference material BAM-Y001', Ed. H. Kipphardt, Certification Report, BAM, Berlin, 2004.

[10] Certificate BAM-Y001, BAM, Berlin, 2004.

[11] Certificates and Certification reports, http:// www.bam.de/pdf/service/referenzmaterialien/ zertifikate.pdf, BAM, Berlin, 2009. 